\title{
When do the USPTO examiners cite as the EPO examiners? An analysis of examination spillovers through rejection citations at the international family-to-family level
}

\author{
Tetsuo Wada ${ }^{1,2}$ (D)
}

Received: 16 December 2019 / Published online: 14 September 2020

(c) The Author(s) 2020, corrected publication 2020

\begin{abstract}
This paper empirically examines coincidences between "rejection citations" (i.e., those cited as grounds for rejections) added by the United States Patent and Trademark Office (USPTO) and "X/Y patent citations," which are also added as grounds for rejections at the European Patent Office (EPO) within the same patent family, based on more than forty thousand families of triadic application sample. We consider the release timing of European search reports and the timing of rejection actions by the USPTO for the same family of patent applications. We find that the frequency of rejection (X/Y-equivalent) citation coincidences between the USPTO and the EPO according to family-to-family citation criteria increases after the release of search reports by the EPO. It suggests that the US examiners capture spillovers of search efforts from the EPO, namely, the USPTO examiners rely on prior art information collected and disclosed by the EPO. The results also reveal that International Search Reports (ISRs) prepared for Patent Corporation Treaty (PCT) applications, as well as applicant-submitted citations, play important roles for the convergence of rejection citations between the two patent offices. We furthermore find that the US examiners are less likely to add the same patent citations as the EPO examiners when rejections are persistently repeated at the USPTO. The methodology in this paper introduces the novel use of patent examiner citations to compare examiners' citing behavior across jurisdictions.
\end{abstract}

Keywords Rejection citation - Examiner citation - Patent citation · Examination spillovers · $\mathrm{X} / \mathrm{Y}$ citations $\cdot \mathrm{DOCDB}$ patent family $\cdot$ Family-to-family citations $\cdot$ Trilateral offices ·

Triadic patent

JEL Classification K29 - O33 · O34

Mathematics Subject Classification 91D30

Tetsuo Wada

tetsuo.wada@gakushuin.ac.jp

1 Faculty of Economics, Gakushuin University, 1-5-1 Mejiro, Toshima-ku, Tokyo 171-8588, Japan

2 Max Planck Institute for Innovation and Competition, Marstallplatz 1, 80539 Munich, Germany 


\section{Introduction}

An internationally valuable patentable invention is often filed as international patent applications and examined in many jurisdictions. A series of prior art searches for the same invention is conducted separately by different patent offices in each jurisdiction, except for those conducted through international agreements such as the European Patent Convention (EPC), the Patent Corporation Treaty (PCT), and Patent Prosecution Highways (PPHs). As a result, separate citations are added to the same family of patent applications in a sequential and/or parallel manner across patent offices. As Wada (2018) has revealed, patent examiners at the trilateral offices of the EPO, the USPTO, and the Japan Patent Office (JPO) tend to cite different prior arts to reject applications in the same patent families, even though the general patentability criteria of novelty and inventive step are close together. "Rejection citation," namely, citations made by examiners to indicate specific prior arts to reject applications, are widespread to the extent that, for example, approximately only $20 \%$ of rejection citations employed at the USPTO coincide with those equivalent X/Y citations for rejections used at the EPO, even after consolidating at family-to-family citation levels (Wada 2018). The discrepancies of rejection citations and X/Y citations become larger when the technological complexity of an application increases (Wada 2018), which can be attributable to limited resources per application by examiners for each application (Marco et al. 2016; Wada 2016; Frakes and Wasserman 2017).

Such apparent discrepancies between rejection citations employed at different offices lead to positive research questions as well as normative questions for the institutional design of international patent examination systems, where a significant amount of effort is spent to review a family of international patent applications out of a single invention across different patent offices simultaneously or sequentially. Examiners can refer to the result of prior art search conducted at other offices, conditional on its availability. In other words, there are opportunities for following examiners to exploit search effort conducted elsewhere, if a prior search outcome by a preceding examiner becomes available for them. Then, a positive question can be raised about whether the following examiner who can observe previous search outcome is more likely to conclude with the same set of previous citations than without a previous examination outcome. This is not obvious, since the following examiner may instead find it easier to generate a different set of citations if the follower can save effort on the revealed prior art and can redeploy search effort for other relevant prior arts that have been looked over by previous examiners. ${ }^{1}$

Beyond this positive question, a normative question can be raised further about whether the potential increase or decrease of citation discrepancies with sequential references between examiners implies a more "complete" prior art search. The answer is indeterminate a priori because the availability of an examination result might induce "shirking"2 by

\footnotetext{
1 A hypothetical academic refereeing process can be illustrative. If two reviewers assigned for the same manuscript are given a sequence where the following reviewer has an opportunity to refer to an earlier recommendation prepared by a preceding referee, the following referee, who is supposed to have different expertise and viewpoints, can rely on the existing evidence, but may still try to provide a different perspective or a prior art with better relevance, as it is the expected value-added as a second referee.

2 The EPO Examination Guidelines state that supplementary search reports must in most cases be prepared on top of international search reports drawn up elsewhere. The Guidelines also explicitly state that "As a general rule, the EPO tries to avoid any superfluous work and duplication of work and relies on the efficiency and quality of the international searches to the largest extent possible" (EPO Guidelines for Examination, Part B, Chapter II, 4.3.2). It suggests a difficult balance between trying more complete search with additional effort and saving duplicative search effort.
} 
follow-on examiners, and subsequent examiners may give up possibilities to find a more relevant prior art by their independent search with better access to relevant information later. More "lenient" examination at a later stage may result in more overlapped citations across different offices, although the results can be less comprehensive, compared to what could be potentially found as a combined set of relevant prior arts.

There are no previous studies on patent citations and international patent examination systems from such parallel or sequential perspectives with potential spillovers between patent offices. ${ }^{3}$ As a direct policy analysis, it would be ideal if we can measure the efficiency gains when an examiner can refer to search outputs prepared by another examiner. However, this normative question can be tackled only after we scrutinize in what case and in what way examiner behavior is changed with the availability of previous search output. If an examiner does not change any behavior and always produces the same set of rejection citations regardless of the availability of a search report, the choice of examination sequence (parallel or sequential) does not matter as a normative question. Therefore, between positive and normative questions above, the positive question should come under scrutiny first. This paper is intended to be the first empirical step toward the positive question. Simply put, this paper tries to quantify spillovers from the EPO to the USPTO empirically by focusing on the convergence of rejection citations between the two.

There is very limited existing knowledge on how examiners in a patent office rely on prior citations generated by applicants and other offices (Cotropia et al. 2013). This paper proposes to track examiner citations used for rejections across patent offices. Generally, we can evaluate whether an examiner of one office utilizes the same prior art for rejecting the same patent application (i.e., patent applications in the same patent family). When the same patent citation is more likely to be employed at different patent offices if a preceding search outcome is available for the following office, we can infer that there are spillovers between patent examination results. ${ }^{4}$ In this paper, we first summarize the coincidences of rejection citations at the aggregate level. Then, we study those patent family citations added by the USPTO for rejection (i.e., rejection patent citations, or X/Y equivalents). We examine whether each US rejection citation coincides with $\mathrm{X} / \mathrm{Y}$ cited families given by European search reports (ESRs) ${ }^{5}$ for the same citing patent family, with special attention to the timing of ESRs and office actions by the USPTO, along with several control variables. By way of comparing USPTO rejection citations (at the level of international family-tofamily citations) with prior art search results conducted by the EPO before and after the release of the ESRs, we can first make a reasonable inference concerning the existence of search result spillovers from the EPO to the USPTO, leading to convergent citations.

This paper contains several research questions with regards to whether and how the convergence of rejection citation can exist, such as: (1) Is a USPTO office action after the release of search reports by the EPO more likely to reflect the same family-level patent citations added by the EPO, compared with pre-ESR (prior to EPO's search reports) office actions at the USPTO? Put differently, do we observe a convergence of patent citations between the two offices? (We focus on unidirectional spillovers from the EPO to the

\footnotetext{
3 A recent article acknowledges the need to study spillovers between patent offices as a future topic (Gimeno-Fabra and van Pottelsberghe de la Potterie 2020).

4 Note that existence of spillover does not always mean reduction in citation discrepancies, because a subsequent examiner may be able to add different citations by redistributing resources to issues that can be ignored previously.

${ }^{5}$ European search reports in this article include ISRs drawn up by the EPO. Although this is inaccurate in a legal sense, this definition is consistent with the focus of this article, which is (potential) information spillovers from the EPO to the USPTO.
} 
USPTO due to data limitations). (2) Do applicant-submitted citations contribute to the convergence of rejection citations? (3) Do we find any difference in the level of convergence with the geographical source of a patent application, and/or technological fields? (4) The PCT system requires that an International Search Report (ISR) should be prepared for a PCT application at the time of international publication. Whereas ESRs often serve as ISRs, do ISRs (prepared also by other authorities such as the USPTO and the JPO) affect the coincidences of rejection citations between the EPO and the USPTO?

This paper proceeds as follows. First, prior literature is briefly reviewed. Examiner patent citations are at the frontier of research in this field, yet there are not many existing studies on rejection citations, especially from international perspectives. Next, the motivation of this study is explained further concerning the positive question above on the convergence of rejection citations and international citation spillover. Since international patent examination systems are quite complex, the basic institutional structure relevant to this study including the international patent application routes, the PCT system, search reports, U.S. office actions, and resulting rejection citations is summarized. The data used for this study is next explained. Then, a simple aggregate comparison is presented, which suggests the existence of examination spillover. The distribution of the timing of US first office actions relative to search reports issued by the EPO is highlighted as well. To incorporate other conditions, regression analyses are conducted and results will be presented. Conclusion follows.

\section{Background on studies of patent citations}

This paper focuses on the growing research attention within patent citation study, with special attention placed on examiner citations used for rejections. The varieties within patent citations, such as applicant citations and examiner citations, have recently been studied (Alcacer and Gittleman 2006; Thompson 2006; Criscuolo and Verspagen 2008; Hegde and Sampat 2009; Lemley and Sampat 2012; Cotropia et al. 2013; Cotropia and Schwartz 2018, Azagra-Caro and Tur 2018; Kuhn et al. 2020). One of the recent research frontiers is the distinction within examiner citations. Whereas examiner citations are considered to be noisy as a means for measuring knowledge flow between inventors, examiner citations have been shown to have an advantage over inventor citations for measuring the value of patents (Hegde and Sampat 2009). Recently, examiner citation as a basis of rejection gains attention as an even better indicator of patent values (Cotropia and Schwartz 2018).

US examiners should indicate specific prior art on which they rely as the reason for rejections, if they reject, in particular, the US Code Title 35 "102" novelty rejections, "103" obviousness rejections, and statutory double patenting rejections. Namely, they must clearly show the reasons for an applicant's rejection if it is attributable to the prior art. At the USPTO, Sect. 706 "Rejection of Claims" of the Manual of Patent Examining Procedure (MPEP) states that "In rejecting claims for want of novelty or for obviousness, the examiner must cite the best references at his or her command." There is no official name for this category of citations, ${ }^{6}$ but recent work (Cotropia and Schwartz 2018) calls it as "rejection citation," or "rejection patent" if a corresponding prior art is a patent. This data

\footnotetext{
6 There have been studies focused on the category of examiner citations. For example, "For certain statutory rejections, the examiner will cite in the Office action the previous patent documents and/or non-patent literature references to support the rejection" (Lu et al. 2017), without naming the exact type of examiner citations in a compactly and inclusively. "Citations used by examiners in rejections" (Cotropia et al. 2013) refer to the same meaning, which is later called as "rejection citation" in another article (Cotropia and
} 
has been made available and draws attention by the recently released office action database of the USPTO ( $\mathrm{Lu}$ et al. 2017). However, to the best knowledge of the author, there has been no previous work that tries to combine examiner patent citation data across different jurisdictions, except the above-mentioned article (Wada 2018).

Examiner citations for refusals, which are assigned special categories of " $\mathrm{X}$ " and "Y"7 at the EPO and other offices such as the JPO, flags the same meaning for US rejection citation. This is because examiners are required to follow exact standards to add special citation categories, such as the EPO's Guidelines for Examination. According to the manual, examiners must indicate specific reasons to refuse patent claims, e.g., lack of novelty or inventive step. ${ }^{8}$ Because the standards of novelty and inventive step are similar ${ }^{9}$ between the offices, the citation categories can be the common ground for comparisons of citations across offices. Although there are differences of patentability standards between the EPO and the USPTO in a limited number of technological fields, such as in software patents and biological patents, we move on to analyses on the assumption that the EPO X/Y citation categories are essentially identical to rejection citations at the USPTO. ${ }^{10}$

Given that rejection criteria are very close together between the EPO and the USPTO and given also that important inventions lead to multiple patent applications in many jurisdictions including the two, a question can be raised concerning the determinants of discrepancies ${ }^{11}$ between rejection citations made to the same family of patent applications (Wada 2018). This adds a viewpoint to the growing number of comparative studies on patent prosecution systems (Azagra-Caro and Tur 2018; Gimeno-Fabra and van Pottelsberghe de la Potterie 2020). Moreover, another question should be raised about interdependence, if any, between citations for rejections between the two offices. This involves a combined

Footnote 6 (continued)

Schwartz 2018). They are virtually equivalent to a combined set of X or Y citations at the EPO, in the sense that specific prior arts constitute the reason to reject.

$7 \mathrm{X}$ and Y indicate "Particularly relevant documents," as specified by the EPO Guidelines for Examination (Part B, Chapter X, 9.2.1).

8 See, for example, the EPO Guidelines for Examination Part C, Chapter III, 4. First communication, Part B, Chapter III, 1.1 Opinions in relation to the search report, and Part B, Chapter II, 2 Objective of the search. ESRs provide patentability information for applicants, as Part B, Chapter II, 2 specifies that the "objective of the search is to discover the state of the art which is relevant for the purpose of determining whether, and if so to what extent, the claimed invention for which protection is sought is new and involves an inventive step." Thus, X/Y citations constitute clear reasons to reject.

9 The term "novelty" is identical between the EPO and the USPTO, and "inventive step" at the EPO is usually interchangeable with "nonobviousness" at the USPTO. For example, the Patent Cooperation Treaty (PCT), Article 33, states that "The objective of the international preliminary examination is to formulate a preliminary and non-binding opinion on the questions whether the claimed invention appears to be novel, to involve an inventive step (to be nonobvious), and to be industrially applicable."

10 This idea of international citation comparison was first proposed at the ISSI Wuhan conference by Wada (2017).

11 The determinants of discrepancies between rejection citations internationally were partially analyzed in a previous study (Wada 2018), but more work is needed with additional perspectives. For example, examiners have been relying on different patent classification systems, such as the International Patent Classification (IPC), the European Classification (ECLA), and the United States Patent Classification (USPC). The EPO and the USPTO have developed a joint classification system, the Cooperative Patent Classification (CPC), as a means to harmonize classification systems. Since the CPC facilitates a standardized way of storing information, the two offices are expected to converge on how to retrieve prior art information. Although we can expect the effect, i.e., a reduced divergence of rejection citations between the two after implementation of the CPC, the sample period of this study until 2013 does not allow analysis on it. This viewpoint is worth noting, however, and the author thanks a referee for pointing out this perspective. 
perspective on international patent examination systems, which is different from international comparisons in a simple parallel way.

\section{Background on international patent applications and prosecutions}

The basic empirical question is whether and how examiner citations for rejections could change if a prior search outcome is available from another office for the same family of a patent application. International application and prosecution systems are complex, and the institutional details matter. In particular, even only between the EPO and the USPTO, there are several potential channels for the following examiner to have access to a preceding search outcome in a variety of ways, and therefore we need to specify routes of international applications and document sources for our research purpose. First, the distinction between applications based on the Paris convention and applications through the $\mathrm{PCT}^{12}$ should be noted, as the PCT specifies different stages of international prosecutions, and also provides international search reports. Second, the EPO has three major document types that accommodate search reports prepared by the EPO, whereas the USPTO does not issue search reports separately from its examination outcomes. The USPTO reports examiner citations on a specific form called PTO-892, but the examiner citations do not necessarily constitute reasons for rejections. Instead, rejection citations at the USPTO are available from the rejection documents in file wrappers on the Public Patent Application Information Retrieval (Public PAIR) database. Finally, the EPO has its examination phase, where additional citations can be added to citations revealed on search reports. However, citations added in the European examination phase are not fully covered in the PATSTAT database, as will be explained in the "Data source" section. Therefore, examination spillover from the USPTO to the EPO cannot be reliably analyzed at this time. We briefly review these conditions below.

First, international applications through the PCT and the Paris convention have major differences in the timing of foreign entries and the availability of ISRs. As can be evident from Fig. 1 below, only one year lag is allowed for international applications through the Paris convention, whereas a PCT application is given a 30-month delay before it enters into its national phase. Besides, an ISR should be prepared for a PCT application by an International Search Authority (ISA), which may be EPO or USPTO or another patent office, and the ISR is published with the international publication by the World Intellectual Property Organization (WIPO). An ISR for a PCT application is transmitted to designated offices, such as the EPO and the USPTO, for national phase prosecution. Therefore, when the EPO is the ISA, i.e., the EPO prepares an ISR, the report transmitted to another office, including the USPTO, is one of the channels of information flows from the EPO.

Second, the EPO has three major document types, A1, A3, and A4, which accommodate European search reports. The EPO A1 document is a European patent application published with a European search report. A3 document is a separate publication of the European search report, issued in a case where the search report is not available at the publication date. A4 is a supplementary search report, which is typically issued for PCT applications with ISRs prepared by other ISAs.

\footnotetext{
12 The Patent Cooperation Treaty (PCT) is consistent with the Paris convention, and the former does not supersede the latter (Patent Cooperation Treaty, Article 1 (2)).
} 


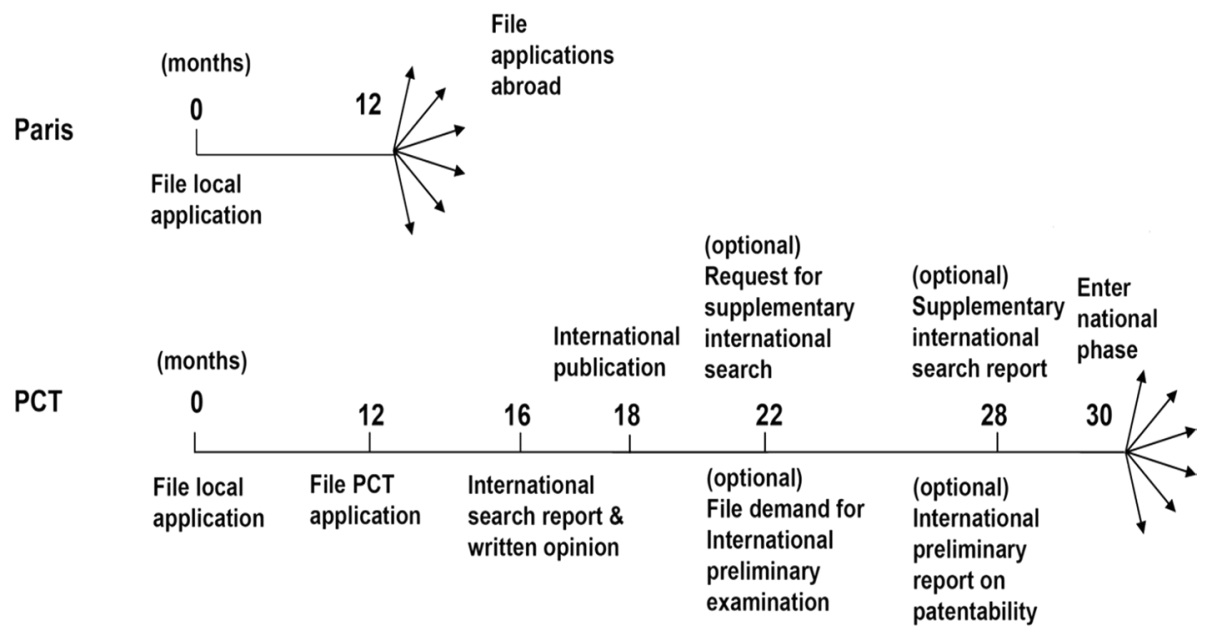

Fig. 1 International applications through the Paris Convention and the PCT. Source: WIPO

Figure 2 below illustrates how EPO A1 and A3 documents can provide spillovers onto the USPTO for an application through the Paris convention (not through PCT). A family of international applications based on the Paris convention is a set of applications claiming a priority in a local jurisdiction. Each application in a family is reviewed separately at each office without a formal information channel as specified in PCT. However, a European search report, either A1 or A3, is to be issued for a European application within an international family of applications. Therefore, when a European search report is available for an examiner at another office who examines its local application in a family, the information can be spillovers from the EPO to another office, including the USPTO. The duty of disclosure and candor is required at the USPTO, which implies a requirement to disclose to the USPTO all information known to an applicant regarding an application, and the information revealed by a European search report becomes a part of the duty. In addition to the applicant's information disclosure statement (IDS, USPTO form 1449) at the time of US application, additional IDS out of a European search report ${ }^{13}$ may thus be reported to the USPTO later. From the main text of "CTNF" (nonfinal rejections) and "CTFR", (final rejections) documents available on the file wrappers of the USPTO Public PAIR database, we can observe citations recognized and employed for rejections by USPTO examiners, possibly as a result of spillovers. These rejection citations constitute a part of examiner citations, which is usually defined by PTO-892 (notice of references cited by examiners) form in statistical analyses.

Next, Fig. 3 illustrates PCT cases, i.e., how ISRs prepared by various ISAs as well as EPO A4 supplementary search reports can provide search results for later examinations. Whereas applicants from the EPC countries cannot choose ISA outside Europe, in many other countries, ISAs can be chosen by applicants globally. For example, US applicants often choose the EPO as ISA for their PCT applications, but sometimes choose to rely on the Korean Intellectual Property Office or the Russian Patent and Trademark Office as an

\footnotetext{
${ }^{13}$ USPTO applicant citation has been defined by this IDS in many statistical studies so far. However, some of the information on IDS originates from search activities by other offices. This category is indeed applicant-submitted, but not applicant-originated.
} 


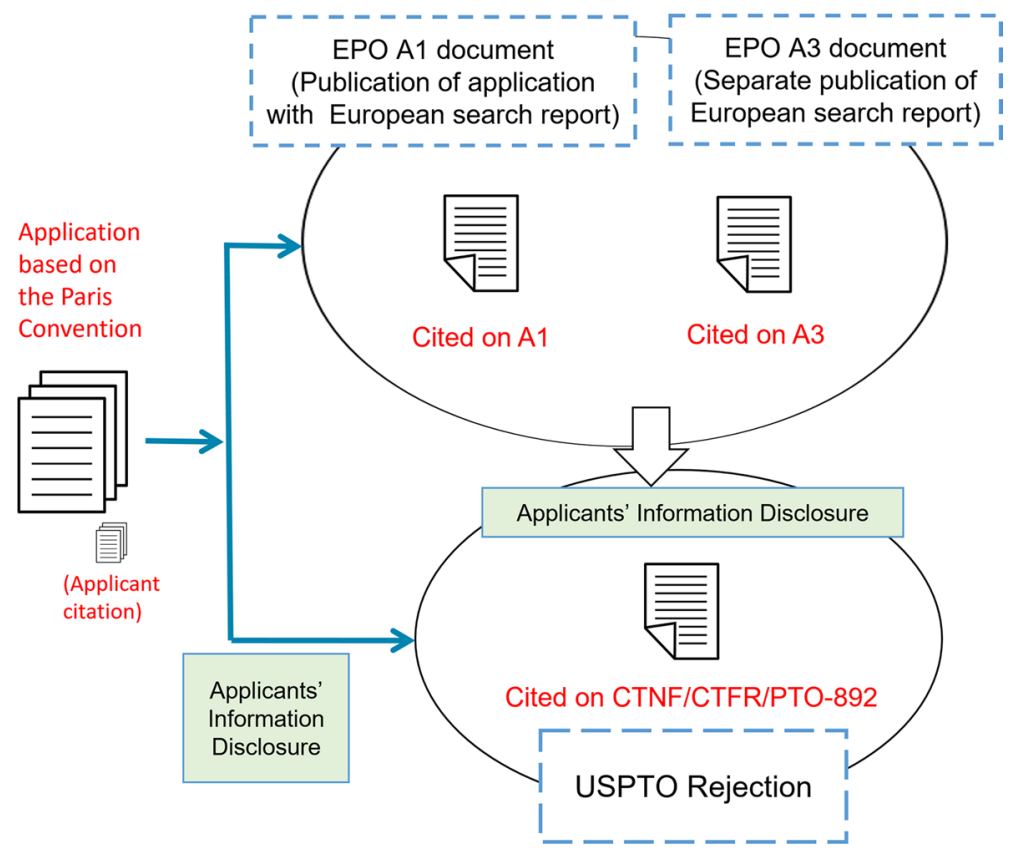

Fig. 2 Potential spillover channels between EPO and USPTO, the Paris Convention route

alternative ISA. As stated before, ISRs are transmitted to another office through WIPO, which can be interpreted as flows from ISAs for national (or regional) examination stages. In addition, the EPO prepares A4 supplementary search reports on top of ISRs prepared by other ISAs ${ }^{14}$. When an applicant receives the result of the EPO A4 supplementary search report, the applicant must notify the USPTO via IDS according to the duty of disclosure for its US counterpart application. This can be another potential channel ${ }^{15,16}$ of spillovers from the EPO to the USPTO.

\section{Data source}

As indicated above, this study takes advantage of a novel large-scale dataset of US rejection patents obtained from rejection documents (the "CTNF" and "CTFR" documents that denote non-final and final rejections, respectively; Graham et al. 2015) available as file wrappers on the "Public PAIR" database of the USPTO to compare patent citations employed by examiners as specific reasons for rejections (Wada 2018). In other words, by way of approximating citation categories of $\mathrm{X} / \mathrm{Y}$ for the USPTO, we are now able to measure convergence

\footnotetext{
14 EPO Guidelines for Examination (Part B, Chapter II, 4.3.2).

15 In a small number of cases, the EPO may act as the Supplementary International Searching Authority as a part of the international phase under PCT, according to the request by applicants. In that case, no supplementary European search report will be drawn up in the European phase ("Euro-PCT Guide": PCT procedure at the EPO, 3.4.005). Yet, in both cases, supplementary search results conducted by the EPO will be made visible by the USPTO.

16 In addition to supplementary searches, an additional citation by the EPO can be added when EPO acts as an International Preliminary Examining Authority (IPEA). This is omitted in this Fig. 3.
} 


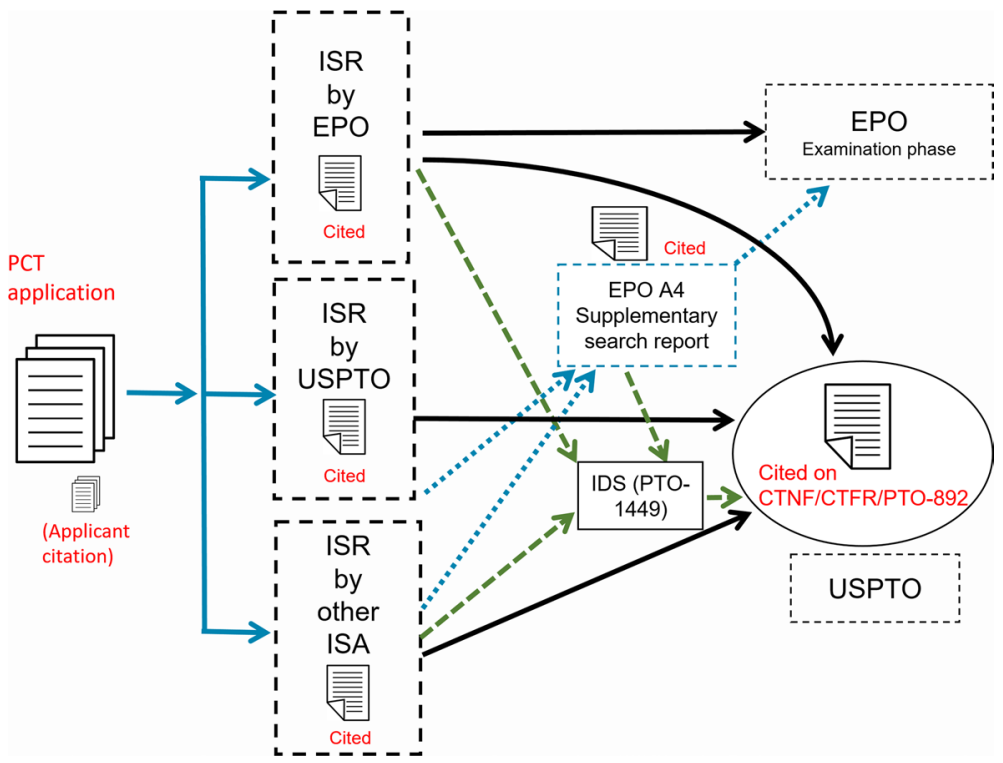

Fig. 3 Potential spillover channels between EPO and USPTO, the PCT route

and divergence of individual rejection reasons used by the two patent offices through familyto-family citations. A similar US X/Y-equivalent database was developed independently by Jeff Kuhn (Thompson and Kuhn 2017), and yet another comprehensive database has now been made available by the USPTO (Lu et al. 2017), which helped to disseminate the idea of rejection citations, or X/Y-equivalent citations. However, neither of these focuses on international citations. International matching and comparisons at the level of family-to-family citations remain unfeasible with those databases. We implemented ${ }^{17}$ optical character recognition and natural language processing to extract $\mathrm{X} / \mathrm{Y}$ equivalents, including international citations, from the file wrapper data at the University of California, Berkeley, by Guan-Cheng Li. We are thus able to evaluate whether the availability of EPO's search reports, which cover most EP citations, influences the prosecution reasons applied by the USPTO through an X/Y equivalent in the US. Combined with the US rejection patent database, the EPO PATSTAT database (Spring 2016) and EPO DOCDB (Backfile 2017 January version) have been used.

The domain of statistical analysis is the set of $\mathrm{X} / \mathrm{Y}$ citations and equivalent rejection citations (cited by 40,557 families), for triadic applications through the PCT and non-PCT applications. Triadic patent applications are defined here as EPO DOCDB families ${ }^{18}$ that

\footnotetext{
17 See Wada (2018) for details of the data set, as the data structure and sources are identical to this article. Parsing algorithm is quite similar to Lu et al. (2017), where key phrases are used as triggers. For example, one or more claims are "rejected" on legal grounds (e.g., "under 35 U.S.C. 102(a)"), with a phrase specifying prior art references, e.g., "as being unpatentable over Kanda (2009/0239176) in view of Nozaki et al. $(1,608,386)$."

18 There is more than one definition of patent families. We primarily rely on the DOCDB family, because of the clarity of patent family ranges to be compared. This approach is identical to the "twin application" idea to study the differential results of patent grants from the triadic offices of the US, the EU, and Japan (Jensen et al. 2005; Webster et al. 2007, 2014; de Rassenfosse et al. 2019). According to the latest PATSTAT Data catalog (2020 Spring), DOCDB family means that "every application belongs to exactly one simple family on PATSTAT" and "all applications which are member of the same simple family do have the same priorities."
} 
contain all of the EPO, USPTO, and JPO applications recorded on EPO's PATSTAT database. The domain of triadic applications was formerly regarded as a standard way of representing patent applications with high economic value (Dernis and Khan 2004) for crossnational comparisons. This is because single-country patenting statistics cannot provide an unbiased measurement in consideration of regional specificities in patent applications and prosecutions around the world. Recently, triadic patents are criticized as a standard (Frietsch and Schmoch 2010), partly because the JPO applications are highly biased toward domestic applicants, and also because the Chinese and Korean shares of international families have recently increased rapidly. However, triadic applications are used in the following analyses for different reasons. First, we need a set of applications where they are examined and given office actions at least both at the EPO and USPTO. Second, we also need a set of applications from outside the two offices, because applicants from Europe and the US tend to have local advantages, for example, as prosecution tactics, from which spillovers between the EPO and the USPTO may be affected. By way of adding a region with many applications, we can evaluate how applications from outside Europe and the US are examined, with possible spillovers between the EPO and the USPTO. The number of applications in Japan was within the top three throughout observation in this study, so the triadic sample is chosen as "EPO and USPTO plus one large patent and trademark office," where the additional office happened to be the JPO.

The citations in this study concern an EPO DOCDB family where only a single DOCDB family ID is observed and where $\mathrm{X} / \mathrm{Y}$ citations (and equivalents) are added by all of the trilateral offices, representing "twin applications approach (de Rassenfosse et al. 2019)." The domain of the study is comprised of 274,100 family citations recorded as rejection citations at the USPTO, found for 40,557 triadic families that have single DOCDB family IDs and priority years 2003-2010. Note that we have oversampled applications from Japan.

Several caveats should be mentioned concerning the data. First, all citation data are patent citations, because of the availability of DOCDB family-to-family citations. Thus, the accuracy of international families depends entirely on the DOCDB family table on PATSTAT. Moreover, PATSAT, our primary data source, records non-patent literature in nonstandardized formats, so we could not consolidate the same non-patent literature across different records. For this reason, we have only employed patent citations at this time. This is a weakness, although most observed examiner rejection citations concern patents only.

Second, only the dates of search reports at the EPO, not those of post-report examinations, are reliably available at present, even on the EPO DOCDB database, which is the mother database for PATSTAT. Also, the EPO citation data during the examination phase are incomplete on DOCDB and PATSTAT. Therefore, we do not utilize examination timing information at the EPO. Search report dates for this study are combined, compared, and checked with the EPO DOCDB backfile and are confirmed to be accurate. We are unable to reliably analyze spillovers from the USPTO to the EPO due to these data limitations.

Third, triadic patent applications are defined here as DOCDB families that contain only one recorded DOCDB citing family. Therefore, any divisional or continuation applications that produce more than one DOCDB family ID exclude the family from the sample. As the economic value of a patent application depends on the probability of the use of divisional or continuation applications, this constitutes a bias in the sample selection. 


\section{Measurement and simple comparison}

A simple aggregate measurement for a particular citing family is the "EPO-USPTO family-to-family rejection citation coincidence ratio," i.e., the ratio of coincidence of $\mathrm{X} / \mathrm{Y}$ citations by the European search reports ${ }^{19}$ over all rejection citations added by the USPTO to the same citing family. To obtain this "EPO-USPTO rejection family-to-family citation coincidence ratio" for an application, we first list X/Y-equivalent US rejection citations added to the application in chronological order during its prosecution history. The number of repeated rejections in its prosecution history at the USPTO is also recorded. The same patent citation is often used repeatedly in the same prosecution history at the USPTO, so there can be multiple records of the same citation pair with different US office action timing. We take the number of all these X/Y-equivalent US examiner citations for the application as the denominator of the ratio for the family of the application. For each US citation, we obtain a citation mapped onto a DOCDB citation pair from the PATSTAT data. We obtain a dichotomy on whether a citation is also coded as X/Y category at the EPO within the same family-to-family citation. When the EPO's search report records the citation as $\mathrm{X} / \mathrm{Y}$, we define the citation as a coincidental X/Y EPO citation pair with the USPTO X/Y equivalent. Then, we take the number of all coincidental X/Y EPO search report citations for the citing family as the numerator of the ratio.

The ratio equals one if all of the X/Y-equivalent rejection citations at the USPTO are also coded as X/Y at the EPO in the same family. The ratio is zero if none of the rejection citations at the USPTO for an application are recognized as X/Y by search reports prepared by the EPO. In summary, this measurement indicates the proximity of a set of rejection citations employed by the USPTO to those X/Y citations indicated by the EPO, within a single family of applications. Figure 4 shows the averages of the citation coincidence ratio over different sets of the sample, comprised of triadic applications with priority in the EPC countries, those with priority in Japan, and those with priority in the US (i.e., geographical sources of applications from each of the trilateral offices). Each of the ratios is calculated according to two stages of US citation timing: pre-ESR (or in PCT applications, pre-ISR prepared by EPO) and post-ESR (or post-ISR prepared by EPO). As is evident from the figure, the ratio increases after the release of EPO's search reports, although the effect is not very obvious for applications from the US. Concerning the basic questions stated at the beginning, the answer for the first one seems to be positive. A simple interpretation of this would be that the US examiners take advantage of the outcome of EPO's search, ${ }^{20}$ especially if an application is first made outside the US. However, because this aggregate ratio does not reflect the difference between PCT and non-PCT applications, and also because this ratio is a simple and aggregate comparison irrespective of European applicant citations or pendency length, we need to analyze at more micro-analytic level, along with control variables. In the next section, we consider the timing of search reports prepared by the EPO relative to USPTO first office actions.

\footnotetext{
19 Again, ESRs here include ISRs prepared by the EPO.

20 The opposite can be true and not inconsistent with the result. Namely, US office actions may be conducted earlier than search reports by the EPO, and EPO examiners may have access to the search results prepared by the USPTO. This will increase the citation coincidence ratio. The apparent gap in the coincidence ratios before and after the release of search reports by the EPO can be interpreted in a way that spillovers from the search reports of EPO to the USPTO office actions are more than the spillovers in the opposite direction.
} 


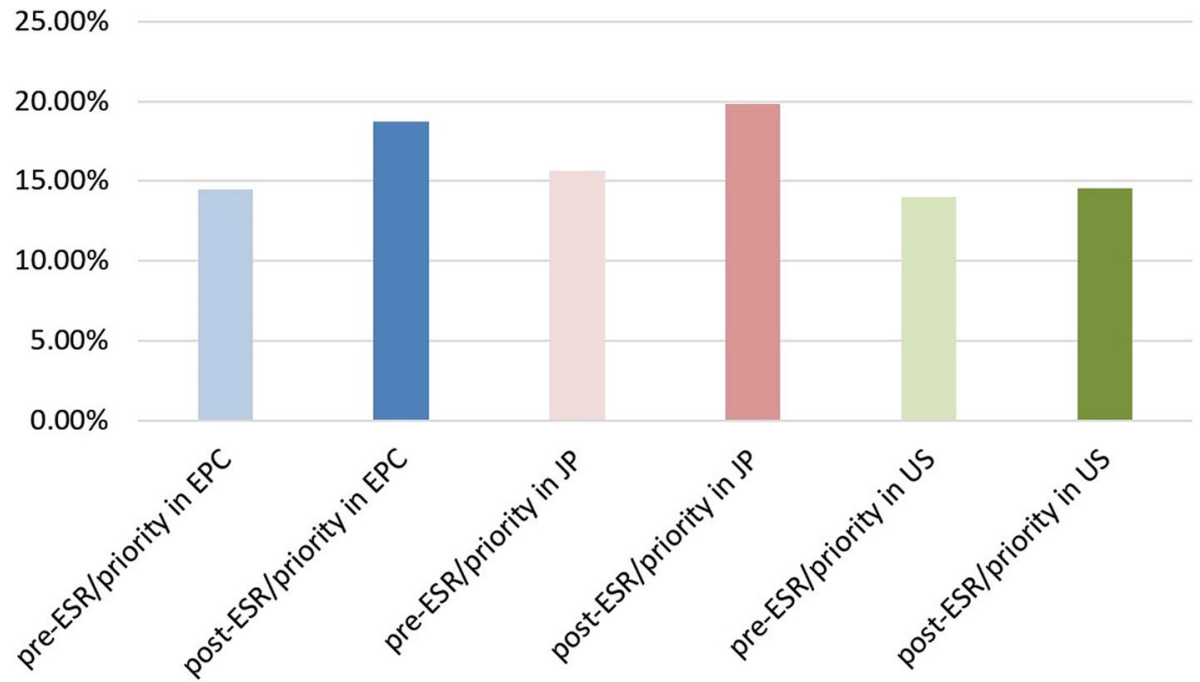

Fig. 4 Average EPO-USPTO X/Y family-to-family citation coincidence ratios

\section{Timing of US first office actions versus European search reports and ISRs}

Albeit the sequence between international and national phase prosecutions was already explained, the actual timing of the search report and US office actions should be further explained. The following Fig. 5 shows the lag distribution (histogram in days) between US first office actions (rejections only) and ESRs or ISRs, namely, European A1, A3, A4, or ISRs prepared by the EPO, for the full sample of this study. The horizontal axis is positive when the US first office action date (mailing-out date) lags behind the publication dates of search reports prepared by the EPO. When European A1, A3, A4, or ISRs prepared by the EPO are all included, US first office actions lag on the average. At the same time, we observe significant overlaps between the office action timings between the two.

On the other hand, as in Fig. 6 below shows, when only European A3 and A4 reports are included and compared, US first office actions take place earlier on the average. There are still significant overlaps, and the mode is around zero, implying that the most frequent occurrence of US first rejections is around the dates of EPO A3 or A4 report issuance.

The two charts above imply that applicants generally find it difficult to predict whether US first office actions take place before search reports by the EPO. From another perspective, PCT applications from Europe or the US have different typical patterns. As is shown by Fig. 7 below on PCT applications from Europe, US office actions are most likely to occur after ISRs prepared by the EPO. This is because the EPO prepares ISRs in time for publications of PCT applications from the EPC countries. From this distribution, we can predict that US examiners expect the availability of ISRs prepared by the EPO for applications from Europe. Given that US first office actions take approximately four years (3.98 years from US filing) in this entire sample, US examiners usually have an advantage of information discovered later than publication concerning relevant prior arts, in addition to the result of European search. 


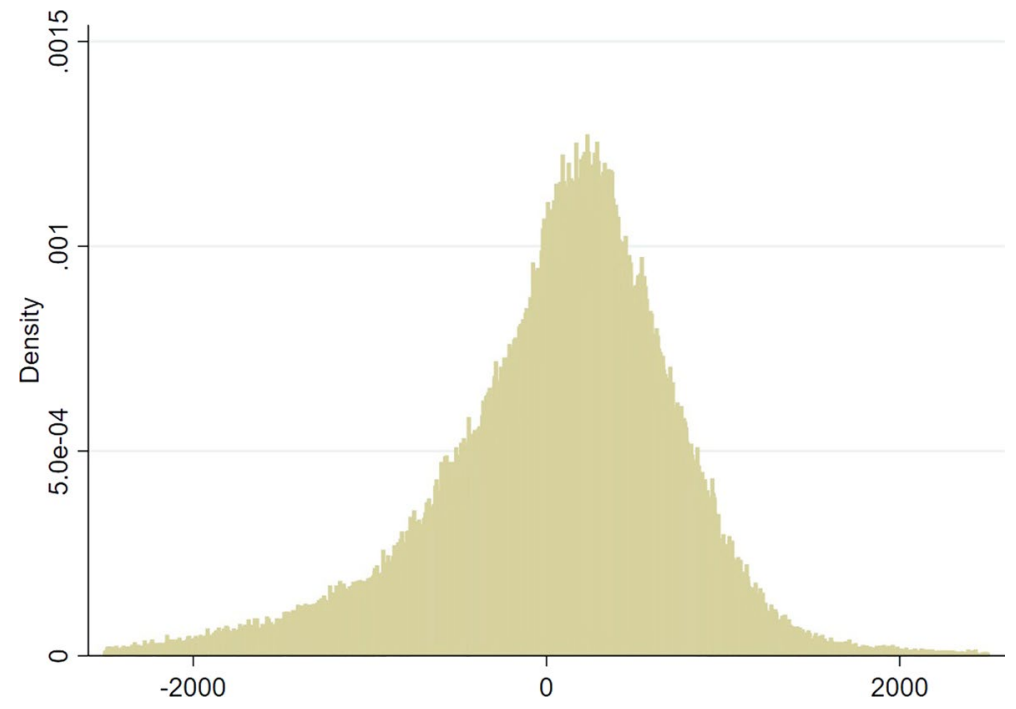

Fig. 5 Time lag (in Days) of US first Office Actions from EPO search report dates (incl. ISRs), all of European A1, A3, A4, and ISRs prepared by EPO being included

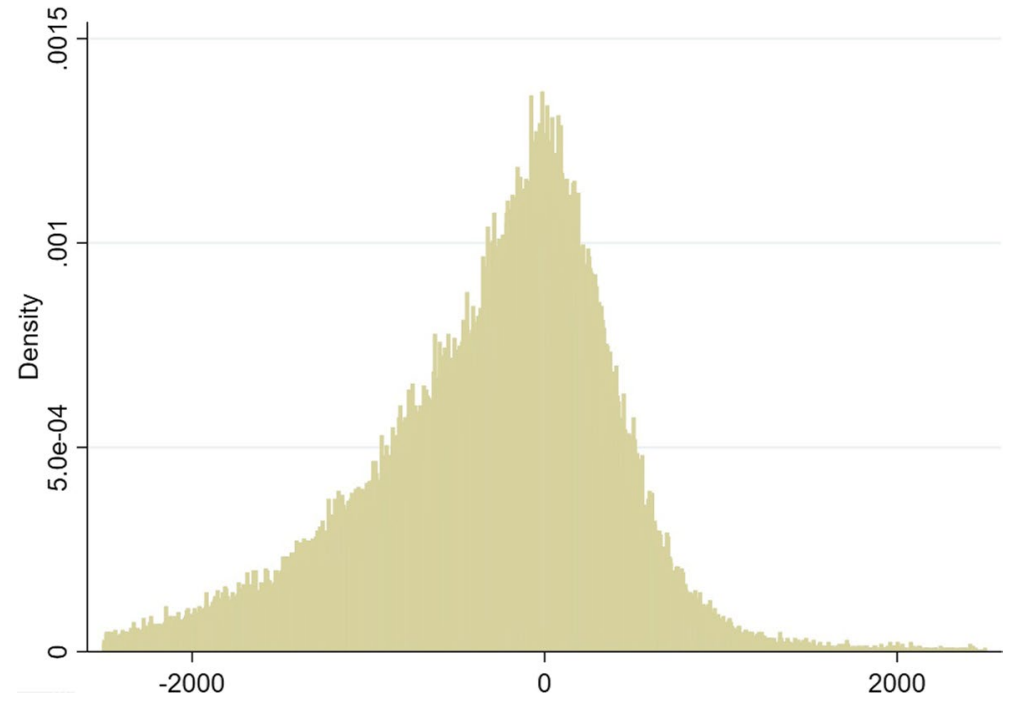

Fig. 6 Time lag (in Days) of US first Office Actions from EPO search report dates (A3 and A4 only)

On the contrary, as is shown by Fig. 8 below on PCT applications from the US only where the USPTO is the ISA, US office actions are most likely to occur before European supplementary search reports (European A4 document). US applicants can choose the EPO as the ISA, but if they choose the USPTO as the ISA, European supplementary search reports are most likely to come later than US first office actions. We can expect that the chance of spillovers from the EPO A4 document to the USPTO first office actions is slim. 


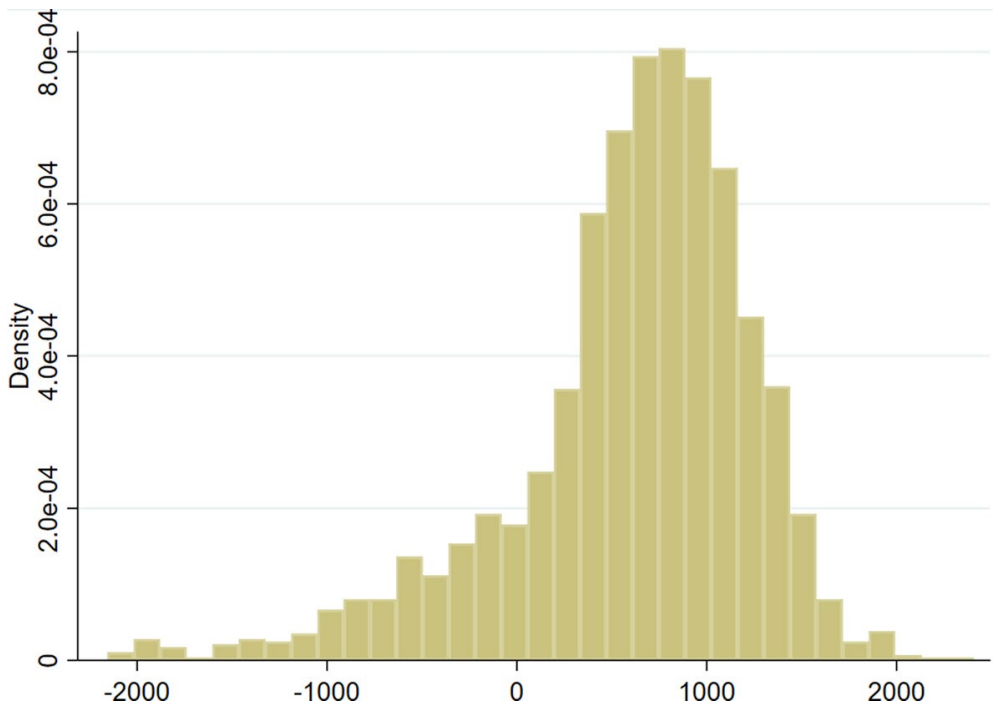

Fig. 7 Time lag (in Days) of US first Office Actions from ISR by EPO as ISA (sample: PCT from EPC countries only)

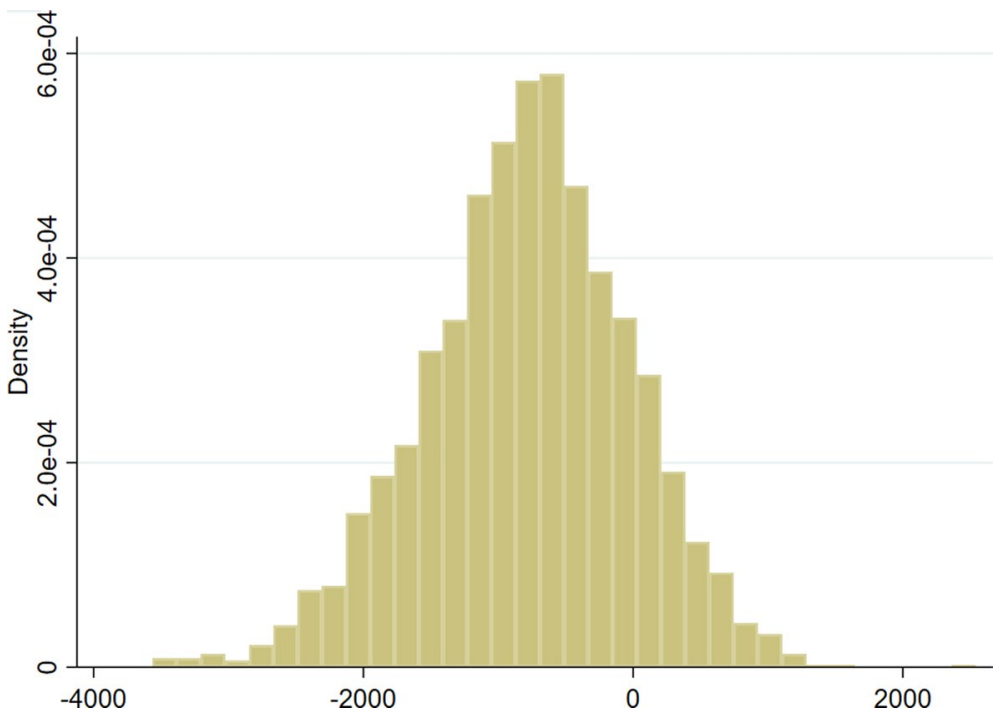

Fig. 8 Time lag (in Days) of US first Office Action from European supplementary search reports (A4) (sample: PCT from the US only) 


\section{Regressions}

\section{Methodology}

To obtain more micro-level insights, we next focus on the dichotomy describing whether or not a US X/Y-equivalent rejection citation is coded as belonging to the $\mathrm{X} / \mathrm{Y}$ category at the EPO as well. By taking this dichotomy as a dependent variable in logit regression, we can analyze correlating factors and their signs. The unit of analysis is a family-to-family citation given at the USPTO as a rejection citation, with office action sequence data and other application-level attributes as explanatory variables. Specifically, let us define $y_{i}$ as a dichotomy taking a value of one when a family of a rejection citation by the USPTO examiners to a triadic application family $i$ coincides with a family of $\mathrm{X} / \mathrm{Y}$ citation added by the EPO search report. Then, the following model can be estimated assuming that the function $\mathrm{F}()$ is a logistic cumulative distribution function. Vectors of explanatory variables are represented by $X_{j}$ and $\beta$ is a coefficient vector such as:

$$
\operatorname{Pr}\left(y_{i}=1\right)=F\left(X_{j} \beta\right)
$$

\section{Explanatory variables $X_{j}$ and main predictions}

We focus on key explanatory variables to analyze convergence and divergence of X/Y citations. One variable is another dichotomy, US_action_after_EP_SEA_date. It takes a value of one when US rejection citation was given at the USPTO after the release of the European search report (abbreviated as "EP SEA" on PATSTAT, and also ISRs prepared by the EPO) for its EP family member application, where applicable. Because of a "search result spillovers" effect, we predicted that the coefficient would be positive. Along with this "before ESR" and "post ESR" distinction, we also employ a dichotomy concerning whether the citation pair is recorded as an applicant citation at the EPO, which can be distinguished as category " $\mathrm{D}$ "1" citation at the EPO. If a citation is submitted by an applicant at the EPO, the applicant is likely to submit the same prior art to the USPTO because of the duty of disclosure in the US. Therefore, citation coincidence between the two offices will increase for European applicant citations. Applicantsubmitted citations in the US, typically defined by PTO-1449 form at the USPTO, are not assigned a variable here, because they are applicant-submitted at the USPTO but not necessarily applicant-originated (See footnote 13 before).

\section{Controls}

We employ a number of control variables. We first employ another variable of the number of rejection actions at the USPTO. This measures the total number of US rejections for a particular rejection citation within a prosecution history. Spillovers from the EPO search report to the USPTO, if any, should occur only once in a prosecution since

21 The category "D" citations can sometimes be found along with X or Y citations at the EPO on PATSTAT. 
typically one report by the EPO is issued for an application. In contrast, rejection reasons could drift through exchanges of actions (e.g., amendments as responses to past rejections), especially at the USPTO. To incorporate these processes, we employ a variable, US_rejection_counts, which is the number of rejections (non-final and final) in a USPTO prosecution history. Because longer exchanges of rejections and responses mean the evolution of bargaining issues in prosecution, we expect the coefficient for this variable to be negative. In order to incorporate a longitudinal effect further, we also employ "us_action_lag_from_appyear" which means the lag in years between filing year and office action year. We also predict the coefficient to be negative.

The PCT requires that a PCT application should be given an international search report prepared by a patent office. If a citation pair is given on an ISR, it will be transmitted to national offices. When an application in a sample is a PCT application and a citation pair is cited in its ISR, a dichotomy isr_cited_dummy is added as indicating that a citation is also listed in ISRs. Since a citation given on an ISR is visible at national and regional offices, we can expect that citations listed on ISRs have a higher probability of coincidence between the EPO and the USPTO, implying a positive coefficient for this variable.

When an application in the sample is not only a PCT application but also has its International Search Authority (ISA) as the EPO, we give a value of one for a dummy variable ISA_EP, which means that a family has the EPO as its ISA. By including this variable, we can evaluate if information from the ISRs from the EPO has any difference. It should be noted that European applicants are required by their rule to ask for search reports from the EPO only (so this variable is always one) if the EPO is the receiving office. Approximately half of the PCT applications from the US choose the EPO as their ISA, whereas most of PCT applications from Japan relies on the Japan Patent Office for their ISA. When a PCT application is given an ISR by other than the EPO, the EPO will issue supplementary search reports (EPO A4 document). Therefore, European search reports are issued for all triadic applications, but the A4 supplementary issuance timing tends to be late when an international search report is already issued by another (nonEPO) ISA.

The location dummies for the priority country, first_EP, first_US, and first_JP, are employed in the full sample estimation. We also controlled for priority years (2003-2010) and the World Intellectual Property Organization (WIPO) 35 technology fields (WIPO 2017) of each family. The variable techn_field_nr_counts is the number of WIPO technology fields covered by the family, representing the breadth of the technology.

We first run linear and logit estimations on the full sample. Then, the PCT sub-sample and Paris sub-sample are used. Next, further sub-samples of applications from the EPC countries, Japan, and the US are used, both for PCT and Paris routes.

\section{Results}

Table 1 shows the results for the full sample, PCT sample, and non-PCT sample over the triadic regions. The first column (Model 1) employs a linear regression, whereas the second row (Model 2) employs LOGIT. Model 3 limits sample range to PCT triadic applications only and Model 4 limits range to non-PCT (Paris-route) sample only. As the first row of the estimation results in Table 1 shows, EPO-USPTO family-to-family rejection citation coincidences are consistently more likely to occur after a release of 
Table 1 Linear and Logit regression, dependent variable: coincidence dichotomy between rejection citations at the EPO and USPTO. Unit of analysis: DOCDB family citation pairs

\begin{tabular}{|c|c|c|c|c|}
\hline & Model 1 & Model 2 & Model 3 & Model 4 \\
\hline Estimation method & Linear & LOGIT & LOGIT & LOGIT \\
\hline Sample range & Full & Full & PCT only & Paris-route only \\
\hline $\mathrm{n}$ & 274,100 & 274,100 & 97,639 & 143,310 \\
\hline families (clusters) & 40,557 & 40,557 & 14,795 & 21,097 \\
\hline us_action_after_EP_SEA_date & $\begin{array}{l}0.0463 * * * * \\
(0.00257)\end{array}$ & $\begin{array}{l}0.353 * * * * \\
(0.0206)\end{array}$ & $\begin{array}{l}0.200^{* * * * *} \\
(0.0332)\end{array}$ & $\begin{array}{l}0.324 * * * * \\
(0.0327)\end{array}$ \\
\hline EP_applicant_cite & $\begin{array}{l}0.0341 * * * * \\
(0.00423)\end{array}$ & $\begin{array}{l}0.226 * * * * \\
(0.0269)\end{array}$ & $\begin{array}{l}0.232 * * * * \\
(0.0487)\end{array}$ & $\begin{array}{l}0.150 * * * * \\
(0.0342)\end{array}$ \\
\hline us_rejection_counts & $\begin{array}{l}-0.00642 * * * * * \\
(0.000829)\end{array}$ & $\begin{array}{l}-0.0492 * * * * \\
(0.00666)\end{array}$ & $\begin{array}{l}-0.0633 * * * * \\
(0.0123)\end{array}$ & $\begin{array}{l}-0.0731 * * * * \\
(0.00906)\end{array}$ \\
\hline us_action_lag_from_appyear & $\begin{array}{l}-0.0033 * * * \\
(0.000991)\end{array}$ & $\begin{array}{l}-0.0268 * * * * \\
(0.00743)\end{array}$ & $\begin{array}{l}0.0204 \\
(0.0135)\end{array}$ & $\begin{array}{l}0.0112 \\
(0.0119)\end{array}$ \\
\hline techn_field_nr_counts & $\begin{array}{l}-0.0102 \\
(0.0103)\end{array}$ & $\begin{array}{l}-0.0754 \\
(0.0764)\end{array}$ & $\begin{array}{l}-0.0938 \\
(0.119)\end{array}$ & $\begin{array}{l}-0.0498 \\
(0.109)\end{array}$ \\
\hline isr_cited_dummy & $\begin{array}{l}0.219 * * * * \\
(0.00738)\end{array}$ & $\begin{array}{l}1.25 * * * * \\
(0.0345)\end{array}$ & $\begin{array}{l}1.47 * * * * \\
(0.0401)\end{array}$ & \\
\hline ISA_EP & & & $\begin{array}{l}0.348^{* * * *} \\
(0.13)\end{array}$ & \\
\hline first_EP & $\begin{array}{l}-0.00806 \\
(0.00545)\end{array}$ & $\begin{array}{l}-0.0692 * \\
(0.0398)\end{array}$ & $\begin{array}{l}-0.209 \\
(0.267)\end{array}$ & $\begin{array}{l}-0.192 * * * * \\
(0.0532)\end{array}$ \\
\hline first_US & $\begin{array}{l}-0.0272 * * * * \\
(0.00479)\end{array}$ & $\begin{array}{l}-0.216 * * * * \\
(0.0375)\end{array}$ & $\begin{array}{l}-0.293 \\
(0.239)\end{array}$ & $\begin{array}{l}-0.186 * * * * \\
(0.0515)\end{array}$ \\
\hline first_JP & $\begin{array}{l}0.00604 \\
(0.00455)\end{array}$ & $\begin{array}{l}0.0333 \\
(0.0339)\end{array}$ & $\begin{array}{l}0.0611 \\
(0.237)\end{array}$ & $\begin{array}{l}0.0644 \\
(0.047)\end{array}$ \\
\hline prio_year_2003 & $\begin{array}{l}-0.0277 * * * * \\
(0.007)\end{array}$ & $\begin{array}{l}-0.202 * * * * \\
(0.0531)\end{array}$ & $\begin{array}{l}-0.297 * * * \\
(0.0993)\end{array}$ & $\begin{array}{l}-0.112 \\
(0.068)\end{array}$ \\
\hline prio_year_2004 & $\begin{array}{l}-0.0165^{* * * *} \\
(0.00624)\end{array}$ & $\begin{array}{l}-0.11^{* *} \\
(0.0443)\end{array}$ & $\begin{array}{l}-0.135 \\
(0.0912)\end{array}$ & $\begin{array}{l}-0.104^{*} \\
(0.0544)\end{array}$ \\
\hline prio_year_2005 & $\begin{array}{l}-0.0173 * * * \\
(0.0058)\end{array}$ & $\begin{array}{l}-0.115^{* * * *} \\
(0.0408)\end{array}$ & $\begin{array}{l}-0.136 \\
(0.0855)\end{array}$ & $\begin{array}{l}-0.0932 * \\
(0.0503)\end{array}$ \\
\hline prio_year_2006 & $\begin{array}{l}-0.00947 \\
(0.00583)\end{array}$ & $\begin{array}{l}-0.0587 \\
(0.0405)\end{array}$ & $\begin{array}{l}-0.104 \\
(0.0854)\end{array}$ & $\begin{array}{l}-0.0417 \\
(0.0491)\end{array}$ \\
\hline prio_year_2007 & $\begin{array}{l}-0.0121 * * \\
(0.00577)\end{array}$ & $\begin{array}{l}-0.0795 * * \\
(0.04)\end{array}$ & $\begin{array}{l}-0.143^{*} \\
(0.0819)\end{array}$ & $\begin{array}{l}-0.0323 \\
(0.0505)\end{array}$ \\
\hline prio_year_2008 & $\begin{array}{l}-0.00101 \\
(0.00588)\end{array}$ & $\begin{array}{l}-0.00316 \\
(0.0401)\end{array}$ & $\begin{array}{l}-0.104 \\
(0.0817)\end{array}$ & $\begin{array}{l}0.0533 \\
(0.0505)\end{array}$ \\
\hline prio_year_2009 & $\begin{array}{l}-0.0117 * * \\
(0.00587)\end{array}$ & $\begin{array}{l}-0.0776^{*} \\
(0.0406)\end{array}$ & $\begin{array}{l}-0.257 * * * \\
(0.0833)\end{array}$ & $\begin{array}{l}-0.0394 \\
(0.0501)\end{array}$ \\
\hline tech_field1 & $\begin{array}{l}0.00629 \\
(0.0109)\end{array}$ & $\begin{array}{l}0.0436 \\
(0.0806)\end{array}$ & $\begin{array}{l}0.112 \\
(0.127)\end{array}$ & $\begin{array}{l}-0.0127 \\
(0.114)\end{array}$ \\
\hline tech_field2 & $\begin{array}{l}-0.0029 \\
(0.011)\end{array}$ & $\begin{array}{l}-0.0253 \\
(0.082)\end{array}$ & $\begin{array}{l}-0.0254 \\
(0.13)\end{array}$ & $\begin{array}{l}-0.0447 \\
(0.116)\end{array}$ \\
\hline tech_field3 & $\begin{array}{l}0.00484 \\
(0.0113)\end{array}$ & $\begin{array}{l}0.04 \\
(0.0859)\end{array}$ & $\begin{array}{l}0.0206 \\
(0.147)\end{array}$ & $\begin{array}{l}0.0039 \\
(0.119)\end{array}$ \\
\hline tech_field4 & $\begin{array}{l}-0.0139 \\
(0.0113)\end{array}$ & $\begin{array}{l}-0.138 \\
(0.0864)\end{array}$ & $\begin{array}{l}-0.154 \\
(0.146)\end{array}$ & $\begin{array}{l}-0.15 \\
(0.121)\end{array}$ \\
\hline tech_field5 & $\begin{array}{l}0.018 \\
(0.0139)\end{array}$ & $\begin{array}{l}0.138 \\
(0.104)\end{array}$ & $\begin{array}{l}0.423^{* * *} \\
(0.192)\end{array}$ & $\begin{array}{l}-0.000155 \\
(0.138)\end{array}$ \\
\hline
\end{tabular}


Table 1 (continued)

\begin{tabular}{|c|c|c|c|c|}
\hline & Model 1 & Model 2 & Model 3 & Model 4 \\
\hline tech_field6 & $\begin{array}{l}-0.0158 \\
(0.0109)\end{array}$ & $\begin{array}{l}-0.132 \\
(0.0818)\end{array}$ & $\begin{array}{l}-0.172 \\
(0.133)\end{array}$ & $\begin{array}{l}-0.177 \\
(0.115)\end{array}$ \\
\hline tech_field7 & $\begin{array}{l}-0.0068 \\
(0.0129)\end{array}$ & $\begin{array}{l}-0.109 \\
(0.111)\end{array}$ & $\begin{array}{l}-0.0713 \\
(0.188)\end{array}$ & $\begin{array}{l}-0.18 \\
(0.158)\end{array}$ \\
\hline tech_field8 & $\begin{array}{l}-0.00537 \\
(0.0112)\end{array}$ & $\begin{array}{l}-0.04 \\
(0.0834)\end{array}$ & $\begin{array}{l}-0.0877 \\
(0.133)\end{array}$ & $\begin{array}{l}-0.058 \\
(0.118)\end{array}$ \\
\hline tech_field9 & $\begin{array}{l}0.0128 \\
(0.011)\end{array}$ & $\begin{array}{l}0.0939 \\
(0.0812)\end{array}$ & $\begin{array}{l}0.0145 \\
(0.13)\end{array}$ & $\begin{array}{l}0.0733 \\
(0.114)\end{array}$ \\
\hline tech_field10 & $\begin{array}{l}0.0186 \\
(0.0113)\end{array}$ & $\begin{array}{l}0.137 \\
(0.083)\end{array}$ & $\begin{array}{l}0.0387 \\
(0.136)\end{array}$ & $\begin{array}{l}0.152 \\
(0.116)\end{array}$ \\
\hline tech_field11 & $\begin{array}{l}0.00946 \\
(0.0154)\end{array}$ & $\begin{array}{l}0.0699 \\
(0.109)\end{array}$ & $\begin{array}{l}0.142 \\
(0.168)\end{array}$ & $\begin{array}{l}0.0366 \\
(0.163)\end{array}$ \\
\hline tech_field12 & $\begin{array}{l}-0.00198 \\
(0.0122)\end{array}$ & $\begin{array}{l}-0.00753 \\
(0.0926)\end{array}$ & $\begin{array}{l}-0.03 \\
(0.151)\end{array}$ & $\begin{array}{l}-0.0975 \\
(0.129)\end{array}$ \\
\hline tech_field13 & $\begin{array}{l}0.00655 \\
(0.0111)\end{array}$ & $\begin{array}{l}0.0545 \\
(0.0821)\end{array}$ & $\begin{array}{l}0.107 \\
(0.128)\end{array}$ & $\begin{array}{l}-0.0229 \\
(0.118)\end{array}$ \\
\hline tech_field14 & $\begin{array}{l}0.0212 * \\
(0.0124)\end{array}$ & $\begin{array}{l}0.146 \\
(0.0891)\end{array}$ & $\begin{array}{l}0.114 \\
(0.135)\end{array}$ & $\begin{array}{l}0.208 \\
(0.134)\end{array}$ \\
\hline tech_field 15 & $\begin{array}{l}0.00712 \\
(0.0136)\end{array}$ & $\begin{array}{l}0.0514 \\
(0.0982)\end{array}$ & $\begin{array}{l}0.089 \\
(0.147)\end{array}$ & $\begin{array}{l}0.035 \\
(0.163)\end{array}$ \\
\hline tech_field16 & $\begin{array}{l}0.00434 \\
(0.0125)\end{array}$ & $\begin{array}{l}0.0329 \\
(0.0914)\end{array}$ & $\begin{array}{l}0.123 \\
(0.137)\end{array}$ & $\begin{array}{l}0.103 \\
(0.153)\end{array}$ \\
\hline tech_field17 & $\begin{array}{l}0.0031 \\
(0.0118)\end{array}$ & $\begin{array}{l}0.0214 \\
(0.0863)\end{array}$ & $\begin{array}{l}0.0297 \\
(0.132)\end{array}$ & $\begin{array}{l}0.0605 \\
(0.127)\end{array}$ \\
\hline tech_field18 & $\begin{array}{l}-0.000578 \\
(0.0169)\end{array}$ & $\begin{array}{l}-0.000465 \\
(0.125)\end{array}$ & $\begin{array}{l}0.0403 \\
(0.174)\end{array}$ & $\begin{array}{l}0.117 \\
(0.238)\end{array}$ \\
\hline tech_field19 & $\begin{array}{l}0.00497 \\
(0.0117)\end{array}$ & $\begin{array}{l}0.0384 \\
(0.0856)\end{array}$ & $\begin{array}{l}0.063 \\
(0.132)\end{array}$ & $\begin{array}{l}0.0287 \\
(0.124)\end{array}$ \\
\hline tech_field 20 & $\begin{array}{l}0.0222 * \\
(0.012)\end{array}$ & $\begin{array}{l}0.158 * \\
(0.0869)\end{array}$ & $\begin{array}{l}0.219 \\
(0.135)\end{array}$ & $\begin{array}{l}0.163 \\
(0.124)\end{array}$ \\
\hline tech_field 21 & $\begin{array}{l}-0.00194 \\
(0.0116)\end{array}$ & $\begin{array}{l}-0.0089 \\
(0.0857)\end{array}$ & $\begin{array}{l}0.0225 \\
(0.132)\end{array}$ & $\begin{array}{l}-0.0584 \\
(0.124)\end{array}$ \\
\hline tech_field 22 & $\begin{array}{l}0.00351 \\
(0.0158)\end{array}$ & $\begin{array}{l}0.0265 \\
(0.117)\end{array}$ & $\begin{array}{l}0.108 \\
(0.182)\end{array}$ & $\begin{array}{l}0.00481 \\
(0.178)\end{array}$ \\
\hline tech_field 23 & $\begin{array}{l}0.0141 \\
(0.0116)\end{array}$ & $\begin{array}{l}0.101 \\
(0.0852)\end{array}$ & $\begin{array}{l}0.0745 \\
(0.133)\end{array}$ & $\begin{array}{l}0.154 \\
(0.122)\end{array}$ \\
\hline tech_field24 & $\begin{array}{l}-0.0106 \\
(0.013)\end{array}$ & $\begin{array}{l}-0.0751 \\
(0.094)\end{array}$ & $\begin{array}{l}-0.0000858 \\
(0.141)\end{array}$ & $\begin{array}{l}-0.067 \\
(0.135)\end{array}$ \\
\hline tech_field 25 & $\begin{array}{l}-0.0014 \\
(0.0119)\end{array}$ & $\begin{array}{l}-0.00957 \\
(0.0883)\end{array}$ & $\begin{array}{l}0.0921 \\
(0.14)\end{array}$ & $\begin{array}{l}-0.0808 \\
(0.124)\end{array}$ \\
\hline tech_field 26 & $\begin{array}{l}0.0142 \\
(0.0121)\end{array}$ & $\begin{array}{l}0.102 \\
(0.0873)\end{array}$ & $\begin{array}{l}0.158 \\
(0.142)\end{array}$ & $\begin{array}{l}0.0242 \\
(0.122)\end{array}$ \\
\hline tech_field 27 & $\begin{array}{l}0.0375 * * * \\
(0.012)\end{array}$ & $\begin{array}{l}0.263 * * * \\
(0.0867)\end{array}$ & $\begin{array}{l}0.086 \\
(0.143)\end{array}$ & $\begin{array}{l}0.273 * * \\
(0.121)\end{array}$ \\
\hline tech_field28 & $\begin{array}{l}0.0154 \\
(0.0119)\end{array}$ & $\begin{array}{l}0.112 \\
(0.087)\end{array}$ & $\begin{array}{l}-0.11 \\
(0.145)\end{array}$ & $\begin{array}{l}0.117 \\
(0.12)\end{array}$ \\
\hline tech_field29 & $\begin{array}{l}0.0118 \\
(0.0117)\end{array}$ & $\begin{array}{l}0.0868 \\
(0.0857)\end{array}$ & $\begin{array}{l}0.0587 \\
(0.133)\end{array}$ & $\begin{array}{l}0.104 \\
(0.123)\end{array}$ \\
\hline tech_field30 & $\begin{array}{l}-0.0186 \\
(0.0131)\end{array}$ & $\begin{array}{l}-0.139 \\
(0.0988)\end{array}$ & $\begin{array}{l}-0.263^{*} \\
(0.157)\end{array}$ & $\begin{array}{l}-0.0992 \\
(0.139)\end{array}$ \\
\hline
\end{tabular}


Table 1 (continued)

\begin{tabular}{lllll}
\hline & Model 1 & Model 2 & Model 3 & Model 4 \\
\hline tech_field31 & 0.00231 & 0.0181 & 0.0351 & -0.0464 \\
tech_field32 & $(0.0125)$ & $(0.0908)$ & $(0.15)$ & $(0.124)$ \\
& 0.00922 & 0.0675 & 0.0963 & 0.0296 \\
tech_field33 & $(0.012)$ & $(0.088)$ & $(0.141)$ & $(0.123)$ \\
& 0.00152 & 0.0136 & 0.06 & 0.0154 \\
tech_field34 & $(0.0129)$ & $(0.0975)$ & $(0.172)$ & $(0.133)$ \\
& 0.00706 & 0.0539 & 0.197 & 0.0283 \\
constant & $(0.012)$ & $(0.0883)$ & $(0.143)$ & $(0.125)$ \\
Log pseudo likelihood & $0.191 * * * *$ & $-1.45 * * * *$ & $-1.65 * * * *$ & $-1.38^{*} * * *$ \\
(Pseudo) R-Sq. & $(0.00715)$ & $(-0.0521)$ & $(0.25)$ & $(-0.0719)$ \\
\hline
\end{tabular}

Robust standard errors in the parentheses, with clustering of citation families

Significance level: $* * * *<0.001, * * *<0.01, * *<0.05, *<0.1$

an EPO's search report. That is, we observe positive and significant coefficients for the explanatory variable, US_action_after_EP_SEA_date, indicating the convergence of US rejection citations to EPO X/Y citations after the release of search reports by the EPO.

The coefficients for EP_applicant_cite are positive and significant. As predicted, applicant-submitted citation at the EPO is positively correlated with the coincidence of rejection citations and $\mathrm{X} / \mathrm{Y}$ citations at the two offices.

The coefficients for $u s \_r e j e c t i o n \_c o u n t s$ are consistent throughout the results, being negative and significant. As predicted, US examiners employ different rejection reasons from those used by the EPO on average, as prosecution takes longer. Therefore, we observe that the longer pendency results in divergence of US rejection citations from EP $\mathrm{X} / \mathrm{Y}$ citations. The additional pendency variable "us_action_lag_from_appyear" is also negative and significant for the full sample, but not always significant for subsamples.

The coefficient for the dummy isr_cited_dummy is consistently positive and significant, and its coefficient value is very high compared to other variables. When an ISR is issued, patent offices can easily have access. Therefore, the coincidence is a necessary outcome. Put differently, even after controlling for this ISR effect, US_action_after_ $E P \_S E A \_d a t e$ has a positive and significant sign, suggesting a stable spillover effect from the EPO to the USPTO. The coefficients for ISA_EP (EPO as an ISA) added for the PCT sample has a positive and significant coefficient, which also suggests spillovers from the EPO through its ISRs.

The location dummies for the priority country show that applications from the US have lower coincidence ratio on the average, except PCT only sample. Whereas ISRs work in favor of convergence of rejection citations for PCT applications, applications through the Paris convention do not have similar spillover channels. The negative coefficient might suggest that US applicants are likely to have local advantages at the USPTO concerning prosecution strategy, which in turn leads to more divergent rejection citations. Concerning technological fields, we do not observe consistent patterns. The technological breadth variable techn_field_nr_counts seems also not relevant. 
Now we limit sample ranges to each first filing region of the EPC countries, Japan, and the US, as is shown in Table 2. According to the first row, US_action_after_EP_ SEA_date has a positive and significant sign, except in Model 9 (PCT from EPC countries only) and Model 11 (PCT from the US only). It may seem to indicate the USPTO examiners do not incorporate information from EP search reports, but considering the timing of search reports and office actions, they are consistent with spillovers, as explained below.

The Model 9 is a variant of Model 8, with the same sample range (PCT from EPC countries only), but with an added dichotomy isr_cited_dummy. As was discussed before, ISRs for PCT applications from the EPC countries are prepared by the EPO. Therefore, this variable isr_cited_dummy is very close to the dependent variable when we focus only on PCT applications from the EPC countries. We still can interpret the result, with a very large positive coefficient on this isr_cited_dummy variable with significance in Model 9, as the USPTO examiners follow search reports prepared by the EPO.

Model 11 employs the PCT sample from the US only. In this model, both isr_cited_ dummy and ISA_EP have a positive and significant coefficient. As was discussed with charts, PCT applications from the US are most likely to receive first office actions earlier, especially when the USPTO is the ISA, where European supplementary search reports are issued typically after first US office actions. Yet, still, a positive ISA_EP coefficient can be interpreted in a way that the EPO has spillovers from its ISRs onto the USPTO. More specifically, when US PCT applicants choose the EPO as their ISA, we can interpret the result as the likelihood of the citation coincidence between the two offices is higher than the case where the USPTO acts as ISA. Controlling for the ISA_EP variable, the coefficient for US_action_after_EP_SEA_date shows whether a supplementary search report (not ISRs by the EPO) prepared by the EPO has a convergence effect. The coefficient is not significant, which is not inconsistent with the general tendency for USPTO examiners to follow the EPO. This is because, in these cases of ISRs for US PCT applications, the EPO issues supplementary search reports, but the supplementary search report is likely to be issued after US first office action (Fig. 8), and therefore the spillovers are unlikely to be captured by the coefficient for US_action_after_EP_SEA_date. Moreover, the number of citations newly added by the supplementary is small. ${ }^{22}$

The coefficients for EP_applicant_cite are positive and significant, except Model 6 (applications from Japan through the Paris Convention). Again, applicant-submitted citation at the EPO is positively correlated with the coincidence of rejection citations and $\mathrm{X} / \mathrm{Y}$ citations at the two offices, although applicants from Japan may have different practices to report citations.

The coefficients for us_rejection_counts are again consistently negative and significant throughout the results. The additional pendency variable "us_action_lag_from_appyear" is not consistently significant for subsamples.

The overall results are consistent with the existence of spillover effect from the EPO to the USPTO, after controlling for many factors. In the limited cases of PCT applications from the US with the USPTO acting as ISA (Model 11), the positive and significant signs

\footnotetext{
${ }^{22}$ It may be possible that US examiners may not find the outcome of EPO's search for US-based applications as valuable as those for applications from outside the US, possibly because examiners have a local advantage in knowledge concerning local applications. Information on examiner characteristics and experience will add value to the analyses here, which is beyond the scope of this article.
} 


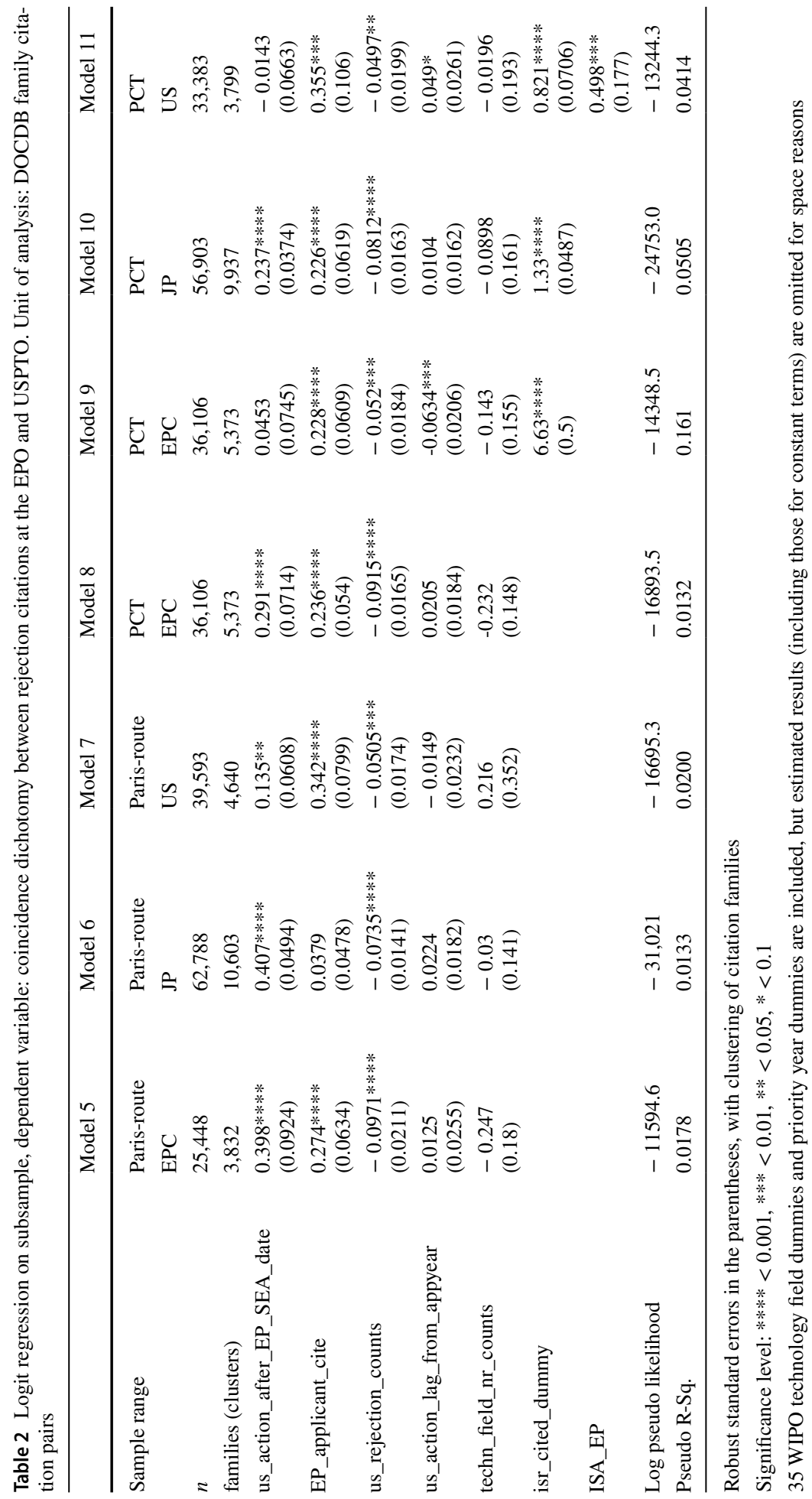


of isr_cited_dummy still indicate that ISRs facilitate the convergence of rejection citations at the USPTO and X/Y at the EPO.

\section{Conclusions}

We find EPO-USPTO convergence of citations after the search report release by the EPO, implying the existence of spillovers from the EPO to the USPTO. The results also show that ISRs facilitate the convergence of rejection citations between the two offices. Also, applicant-submitted citation at the EPO show positive coefficients, implying that they are facilitating the coincidence of rejection citations and $\mathrm{X} / \mathrm{Y}$ citations at the two offices. Thus, the positive question presented at the beginning of this article, namely, whether the following examiner who can observe previous search outcome is more likely to conclude with the same set of previous citations than without a previous examination outcome, clearly has affirmative results.

The results obtained here notwithstanding, we cannot immediately conclude with the normative question presented at the beginning, namely, whether the increased citation concordances between examiners at different offices always imply a more "complete" prior art search. The convergence of citations after the release of EPO's search reports may imply that there is "benefit" by saving search effort by the USPTO. If less search effort at the following office always means "more efficiency," collaborative search mechanisms between patent offices are always beneficial, which have policy implications. However, a combined set of search results can be less comprehensive. What is potentially found by multiple independent searches rather than sequenced and dependent searches is one of the different research topics. This is reserved for future research and may be assessed, for example, by comparing opposition outcomes.

Aside from normative questions, we find other findings, such as the convergence of citations through applicant-submitted prior arts and divergence of citations when prosecution takes longer. Namely, we find that European applicant-submitted ("D" category) citations lead to convergence of rejection citations. We also find the divergence of US rejection patent citations from those at the EPO as the process of prosecution becomes longer, which is typically caused in the US by persistent challenges from applicants appealing repeated rejections.

The results concerning the interdependence of patent prosecutions between major patent offices have been found by a novel use of examiner patent citations, though this can be regarded as only an initial step toward the international design of interdependent institutions. From a theoretical viewpoint, the approach of this study shows potential beyond the narrow field of patent citation studies, in that sequential reviews of prior arts relevant to the same citing documents could result in different citation network structures, dependent on the possibility of information sharing between different citing entities.

Acknowledgements The present study is an extended version of an article (Wada 2019) presented at the 17th International Conference on Scientometrics and Informetrics, Rome (Italy), 2-5 September 2019, with additional materials prepared for a short-term research project "International spillovers between patent examination results" by the Institute for Intellectual Property, Tokyo (Wada 2020). This study has benefited from a research project for the Research Institute of Science and Technology for Society (RISTEX) and the Japan Science and Technology Agency (JST), and also from the project "Building up Innovation Capability and the Design of Incentives: Evidence from Micro-data," undertaken at the Research Institute of Economy, Trade and Industry (RIETI). The author is grateful for helpful comments from the anonymous referees of 
this journal and Setsuko Asami, Stuart Graham, Bronwyn Hall, Dietmar Harhoff, Yoshiaki Kodachi, Alan Marco, Sadao Nagaoka, Yoshimi Okada, Alfons Palangkaraya, Kazuyuki Tanji, Andrew Toole, Stefan Wagner, and the audience at the 13th Annual Conference of the European Policy for Intellectual Property (EPIP) and the Max Planck Innovation and Entrepreneurship Seminar. The author acknowledges financial support from the Japan Society for the Promotion of Science (JSPS) KAKENHI Grant Numbers $18 \mathrm{H} 00889$ and $16 \mathrm{KT} 0092$.

Funding Open Access funding enabled and organized by Projekt DEAL.

Open Access This article is licensed under a Creative Commons Attribution 4.0 International License, which permits use, sharing, adaptation, distribution and reproduction in any medium or format, as long as you give appropriate credit to the original author(s) and the source, provide a link to the Creative Commons licence, and indicate if changes were made. The images or other third party material in this article are included in the article's Creative Commons licence, unless indicated otherwise in a credit line to the material. If material is not included in the article's Creative Commons licence and your intended use is not permitted by statutory regulation or exceeds the permitted use, you will need to obtain permission directly from the copyright holder. To view a copy of this licence, visit http://creativecommons.org/licenses/by/4.0/.

\section{Appendix}

See Table 3 .

Table 3 WIPO technology fields

\begin{tabular}{|c|c|}
\hline Field_number & Field_name \\
\hline 1 & Electrical machinery, apparatus, energy \\
\hline 2 & Audio-visual technology \\
\hline 3 & Telecommunications \\
\hline 4 & Digital communication \\
\hline 5 & Basic communication processes \\
\hline 6 & Computer technology \\
\hline 7 & IT methods for management \\
\hline 8 & Semiconductors \\
\hline 9 & Optics \\
\hline 10 & Measurement \\
\hline 11 & Analysis of biological materials \\
\hline 12 & Control \\
\hline 13 & Medical technology \\
\hline 14 & Organic fine chemistry \\
\hline 15 & Biotechnology \\
\hline 16 & Pharmaceuticals \\
\hline 17 & Macromolecular chemistry, polymers \\
\hline 18 & Food chemistry \\
\hline 19 & Basic materials chemistry \\
\hline 20 & Materials, metallurgy \\
\hline 21 & Surface technology, coating \\
\hline 22 & Micro-structural and nano-technology \\
\hline 23 & Chemical engineering \\
\hline 24 & Environmental technology \\
\hline 25 & Handling \\
\hline
\end{tabular}




\begin{tabular}{ll}
\hline Field_number & Field_name \\
\hline 26 & Machine tools \\
27 & Engines, pumps, turbines \\
28 & Textile and paper machines \\
29 & Other special machines \\
30 & Thermal processes and apparatus \\
31 & Mechanical elements \\
32 & Transport \\
33 & Furniture, games \\
34 & Other consumer goods \\
35 & Civil engineering \\
\hline
\end{tabular}

WIPO (2017, pp. 220-221)

\section{References}

Alcacer, J., \& Gittelman, M. (2006). Patent citations as a measure of knowledge flows: The influence of examiner citations. The Review of Economics and Statistics, 88(4), 774-779.

Azagra-Caro, J. M., \& Tur, E. M. (2018). Examiner trust in applicants to the European Patent Office: Country specificities. Scientometrics, 117, 1319-1348.

Cotropia, C. A., Lemley, M. A., \& Sampat, B. (2013). Do applicant patent citations matter? Research Policy, 42(4), 844-854.

Cotropia, C., \& Schwartz, D. (2018). Patents used in patent office rejections as indicators of value. SSRN. https://ssrn.com/abstract=3274995.

Criscuolo, P., \& Verspagen, B. (2008). Does it matter where patent citations come from? Inventor vs. examiner citations in European patents. Research Policy, 37(10), 1892-1908.

De Rassenfosse, G., Griffiths, W. E., Jaffe, A. B., \& Webster, E. (2019). Low-quality patents in the eye of the beholder: Evidence from multiple examiners (No. w22244). National Bureau of Economic Research.

Dernis, H., \& Khan, M. (2004). Triadic patent families methodology. OECD Science, Technology and Industry working papers, no. 2004/02. Paris: OECD Publishing.

Frietsch, R., \& Schmoch, U. (2010). Transnational patents and international markets. Scientometrics, 82(1), $185-200$.

Gimeno-Fabra, L. \& van Pottelsberghe de la Potterie, B. (2020) Decoding patent examination services, Economics of Innovation and New Technology. DOI: https://doi.org/10.1080/10438599.2020.1766183.

Graham, S. J. H., Marco, A. C., \& Miller, R. (2015). The USPTO patent examination research dataset: A window on the process of patent examination. Georgia Tech Scheller College of Business research paper, no. WP 43.

Frakes, M. D., \& Wasserman, M. F. (2017). Is the time allocated to review patent applications inducing examiners to grant invalid patents? Evidence from micro-level application data. Review of Economics and Statistics, 99(3), 550-563.

Hegde, D., \& Sampat, B. (2009). Examiner citations, applicant citations, and the private value of patents. Economics Letters, 105(3), 287-289.

Jensen, P. H., Palangkaraya, A., \& Webster, E. (2005). Disharmony in international patent office decisions. Federal Circuit Bar Journal, 15, 679.

Kuhn, J. M., Younge, K. A., \& Marco, A. C. (2020). Patent citations reexamined. RAND Journal of Economics, 51(1), 109-132.

Lemley, M. A., \& Sampat, B. (2012). Examiner characteristics and patent office outcomes. Review of Economics and Statistics, 94(3), 817-827.

Lu, Q., Myers, A. F., \& Beliveau, S. (2017). USPTO patent prosecution research data: Unlocking office action traits. USPTO economic working paper, no. 10.

Marco, A. C., Sarnoff, J. D., \& deGrazia, C. (2016). Patent claims and patent scope. USPTO economic working paper, 2016-04.

Thompson, N., \& Kuhn, J. (2017). Does winning a patent race lead to more follow-on innovation? SSRN. https://ssrn.com/abstract=2899088. 
Thompson, P. (2006). Patent citations and the geography of knowledge spillovers: evidence from inventorand examiner-added citations. The Review of Economics and Statistics, 88(2), 383-388.

Wada, T. (2016). Obstacles to prior art searching by the trilateral patent offices: Empirical evidence from International Search Reports. Scientometrics, 107(2), 701-722.

Wada, T. (2017). The choice of examiner citations for refusals: Evidence from the trilateral offices. In Proceedings of ISSI 2017: The 16th international conference on scientometrics and informetrics (pp. 950957). Wuhan University, China.

Wada, T. (2018). The choice of examiner patent citations for refusals: Evidence from the trilateral offices. Scientometrics, 117, 825-843.

Wada, T. (2019). Convergence between rejection citations and X/Y citations across patent offices. In Proceedings of ISSI 2019---The 17th International Conference on Scientometrics and Informetrics, Sapienza University, Rome, Italy, 2163-2170.

Wada, T. (2020). International spillovers between patent examination results: Evidence from Triadic X/Y citations (in Japanese language). Report of the 2019FY Collaborative Research Project on Harmonization of Industrial Property Right Systems. Institute of Intellectual Property.

Webster, E., Jensen, P. H., \& Palangkaraya, A. (2014). Patent examination outcomes and the national treatment principle. RAND Journal of Economics, 45, 449-469.

Webster, E., Palangkaraya, A., \& Jensen, P. H. (2007). Characteristics of international patent application outcomes. Economics Letters, 95, 362-368.

World Intellectual Property Organization. (2017). World intellectual property indicators 2017. WIPO publication, no. 941E/17. 